\title{
Envelhecer Sorrindo - Uma Experiência de Desenvolvimento Artístico: Fazendo da Sala de Espera um Ambiente de Criação
}

\author{
Envelhecer Sorrindo - An Experience of Artistic Development: \\ Making the Waiting Room a Creation Enviroment
}

\section{RESUMO}

"Uma experiência de desenvolvimento artístico" surgiu, dentro do programa Envelhecer Sorrindo, de uma parceria entre a Faculdade de Odontologia e a Escola de Comunicações e Artes da USP, com o apoio da Comissão de Cultura e Extensão Universitária através das bolsas de Aprender com Cultura e Extensão. A ideia veio à tona em decorrência da exploração das possibilidades artísticas que podem existir nos momentos que antecedem o atendimento odontológico numa sala de espera do Departamento de Prótese da Faculdade de Odontologia da USP. Pensou-se que esses processos criativos poderiam beneficiar a saúde geral do idoso, além de promover uma intersecção didática e cultural entre os alunos dos dois centros estudantis. Executado em duas etapas: a primeira constou de estudo teórico sobre o lugar que o idoso ocupa na sociedade, assim como suas especificidades e possibilidades de ação para, a partir de então, dialogar com esse público. Com base nas informações coletadas, escolhemos a memória como tema central a ser explorado na segunda etapa, que foi concretizada em encontros semanais com os pacientes. A cada encontro era proposta uma nova experiência artística, que buscava descontração e sociabilização possíveis, dentro da tentativa de se atrelar a saúde e o exercício da arte.

Palavras-chave: Idoso. Saúde. Memória.

\section{ABSTRACT}

"An experience of artistic development" has raised inside the "Envelhecer Sorrindo" program as a partnership between Odontology and Arts \& Communication Schools at University of São Paulo, being such experience supported by Dean's Office for Cultural and Extramural Activities, by means of the "Aprender com Cultura" scholarship. The idea popped up due to the artistic possibilities that may emerge in the waiting room of a Prosthesis Department. We thought that the creative process could benefit the total 
health of the elderly besides promoting a didactic and cultural intersection among the students of both centers.This took place in two moments: the first was a theoretical study that searched to identify the place the elderly occupies in our society, as well as its specificities and possibilities and from this point owning the collected information should feel comfortable to dialogue with them. Based on the collected data we picked the memory as mean subject to be explored in the second moment of this project, which took place in the waiting room every week. During each meeting, it was proposed a new artistic experience, aiming on making them relaxed or more socialized besides trying to add health and exercises to that artistic moment.

Keywords: Elderly. Health. Memory.

\section{INTRODUÇÃO}

Com o aumento da expectativa de vida, a população idosa aumentou consideravelmente. Entretanto, o papel dessa população dentro da sociedade não está definido a contento, apesar de ter progredido bastante nos últimos anos.

Muitas pessoas acreditam que a terceira idade represente apenas um período de decadência das habilidades físicas e mentais, transformando a pessoa idosa num grupo homogêneo e improdutivo, preocupado apenas em sobreviver [3].

Preocupado em mudar esse sentimento, surgiu em 1999 - Ano Internacional do Idoso - o projeto Envelhecer Sorrindo. Inicialmente, a sua atividade clínica no Departamento de Prótese da Faculdade de Odontologia dava ênfase aos problemas relacionados com a saúde bucal e a reabilitação protética. Atualmente, além dos atendimentos odontológicos - realizando próteses em média para 250 pessoas por ano -, o Envelhecer Sorrindo realiza uma vez por ano um evento que reúne cerca de 500 pessoas idosas e que tem como objetivo discutir o papel do idoso dentro da nossa sociedade, orientando também sobre questões de saúde envolvidas no processo de envelhecimento.

Os idosos a serem atendidos no programa Envelhecer Sorrindo ficavam com tempo ocioso, aguardando o atendimento odontológico (Figura 1). Essa espera costumava gerar ansiedade, além de solicitar do cirurgião-dentista um período para escutar relatos e dissipar, assim, um pouco dessa ansiedade. Todo esse processo resultava em um aumento do tempo de atendimento e, consequentemente, de espera.

Dentro desse contexto, escolhemos a memória como matéria-prima do nosso trabalho. A memória pode resgatar as experiências significativas de suas histórias, trazendo à tona as narrativas que nos auxiliam na compreensão do momento atual e seus desdobramentos.

Tendo definido memória como tema, uma breve pesquisa nos levou a duas diferentes possibilidades de abordagem: memória cognitiva e memória afetiva. A afetiva se relaciona às recordações e experiências, fatos aos quais estamos ligados emocionalmente, enquanto que a cognitiva está ligada a aspectos imediatos de apreensão de informações, relações lógicas desconectadas do campo sentimental. 


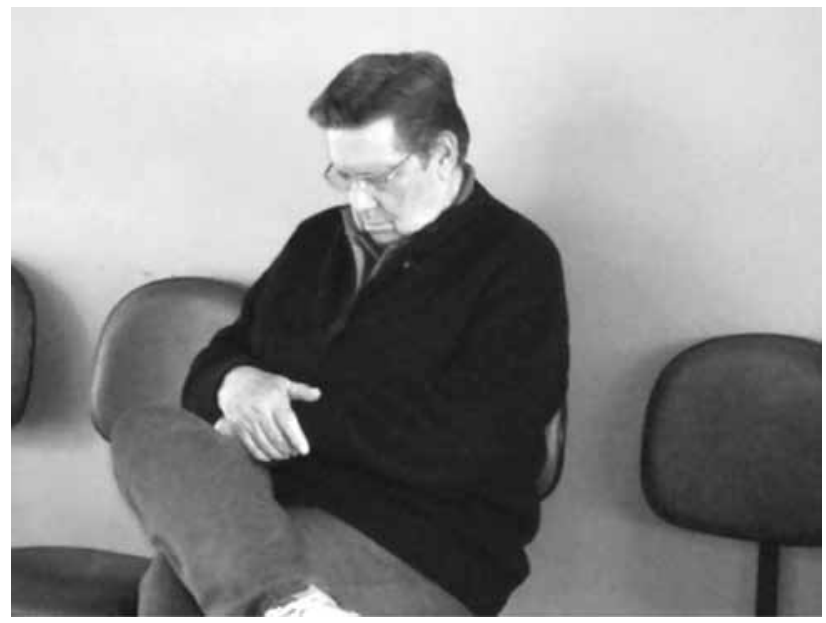

Figura 1 - Tempo ocioso leva o idoso ao sono diurno.

Partindo da ideia de que ambas são importantes e complementares, pensamos em práticas que pudessem abarcar as diferentes abordagens da memória.

\section{ALIANDO SAÚDE À ARTE}

O valor do tratamento odontológico nesse momento da vida pode parecer algo de menor importância, mas não é. Uma pessoa desdentada não consegue alimentar-se adequadamente, podendo dar origem a problemas sistêmicos. Os dentes são elementos importantes para a fala, pois sons como o " $\mathrm{f}$ " e o "v", por exemplo, tornam-se ininteligíveis ao telefone no caso da ausência dos dentes anteriores superiores. Como se isso tudo não fosse suficiente, a questão estética faz com que muitas pessoas idosas não saiam de casa para não ser motivo de chacota. A falta de socialização cria um terreno fértil para a instalação de processos depressivos, indesejáveis quando se imagina um quadro de harmonia familiar.

Nossos encontros durante o atendimento no programa Envelhecer Sorrindo possibilitaram um intercâmbio profissional entre as duas áreas citadas anteriormente, uma vez que nossas atividades foram capazes de apontar um papel novo para a Odontologia no tocante à sua atuação na saúde dos idosos.

A memória (sempre pensando nos dois tipos já citados) possui enorme potência criativa e imagética, sendo por esse motivo passível de ser explorada também como tema para desenvolvimento artístico.

Tomando como premissa a possibilidade de trabalhar o desenvolvimento artístico, optamos por buscar possíveis formas de relacionamento poético com a memória. A aproximação poética com o tema permite que se faça uso de propostas vindas de várias formas de arte, a saber, fotografia, música, literatura, teatro, dentre outras.

No entanto, escolhemos trabalhar a memória através da contação de histórias. Nossa pesquisa fez com que viesse à tona a ideia de narração - conforme descrição de Benjamin [1] -, o compartilhamento de experiências, de palavras. $\mathrm{O}$ trabalho com o ato de narrar é bastante instigante, pois além de indicar outra possibilidade de relação 
cênica, também se mostra capaz de permitir o desenvolvimento dos dois tipos de memória que escolhemos para nos nortear. $\mathrm{O}$ compartilhamento de palavras (sejam estas advindas da experiência pessoal ou da livre criatividade) é capaz de estabelecer e também aprimorar a comunicação entre as pessoas, lembrando quão importante é o combate à depressão na terceira idade. Esse mesmo processo de compartilhamento auxilia ainda as memórias afetiva e cognitiva, posto que, para utilizarmos as palavras e sermos capazes de produzir nossas histórias, recorremos a esses diferentes aspectos da lembrança.

\section{O CENÁRIO E AS PERSONAGENS}

Cadeiras de madeira encostadas na parede, uma grande mesa no centro e uma janela ao fundo compõem o ambiente da sala de espera.

Pessoas idosas de diferentes idades, cada qual com sua história, nesta sala, esperam o atendimento, envoltos em seu mundo do envelhecer onde durante muito tempo tal cenário e seus personagens compuseram uma mesma história, fruto do tempo ocioso (Figura 1).

Este projeto vem, por meio da associação interdisciplinar entre a Odontologia e as Artes Cênicas, atuar nesse cenário, preenchendo o tempo de espera através de atividades lúdicas, beneficiando a saúde da pessoa idosa como um todo, na participação efetiva - socialização - ou apenas no observar a atuação dos outros (Figura 2) - aqueles sem integração direta com aquele grupo/dia.

\section{MATERIAIS E MÉTODOS}

O projeto foi realizado entre os meses agosto de 2009 e julho de 2010 . Na primeira etapa, partimos do estudo interdisciplinar da pessoa idosa na sociedade atual, buscando bibliografias diversas que pudessem nos enveredar pelos campos da Arte e da Saúde. Encontramos como importante base teórica o livro Memória e Sociedade: Lembranças de Velhos, de Bosi [2], que ressalta a importância da memória do idoso na formação da identidade de um povo. Imbuídos por essas pesquisas, usamos a memória como motor principal para as atividades a serem realizadas na sala de espera. No início do primeiro semestre de 2010, promovíamos reuniões para estabelecer as atividades a serem desenvolvidas a cada encontro.

Às terças-feiras pela manhã, antes do início do atendimento clínico dos pacientes, começavam as atividades. Cada encontro tinha como estrutura básica:

" O convite à participação da atividade;

"A apresentação do projeto;

" A apresentação de cada participante;

") A atividade artística em si;

"O registro plástico do encontro (Figura 3). 

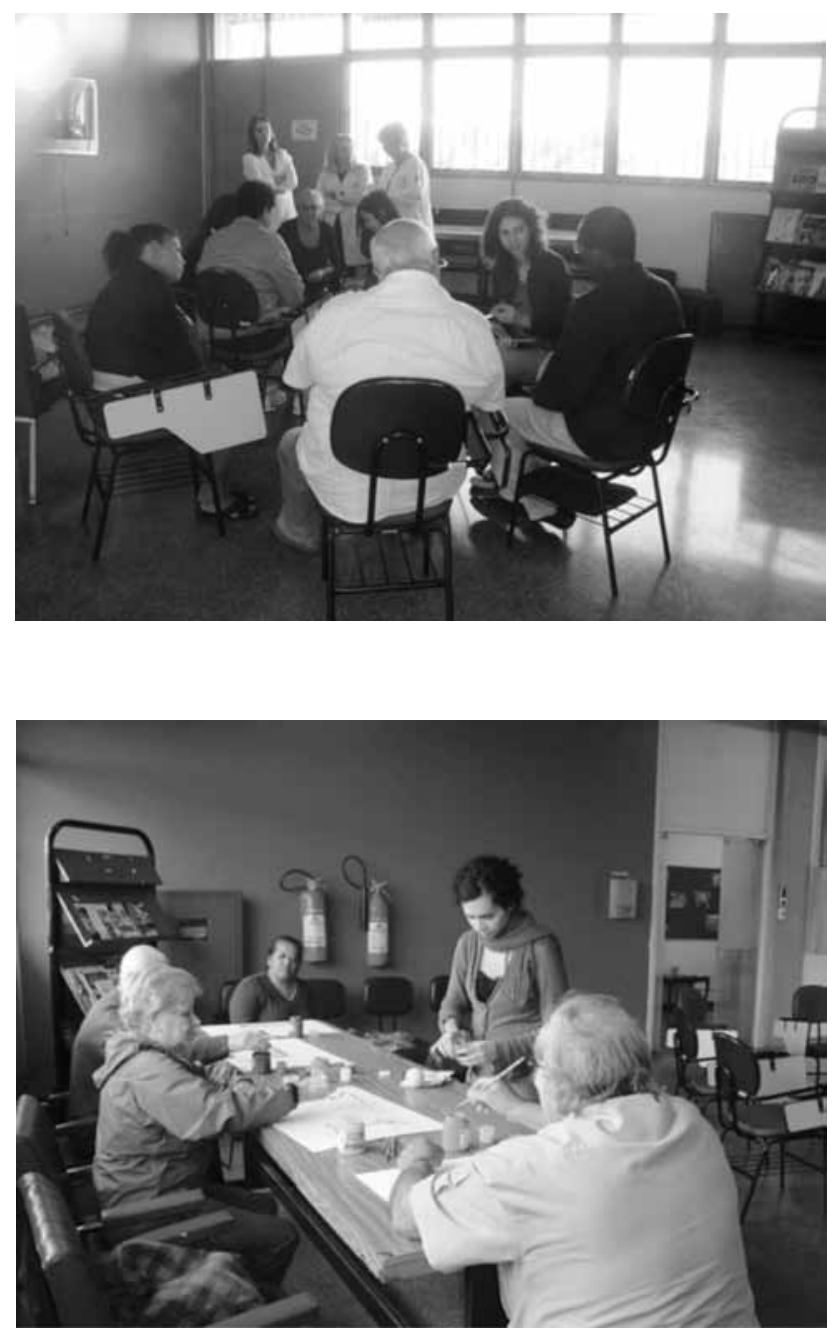

Figura 2 - Interação entre os alunos e pacientes em sala de espera.
Figura 3 - Atividade de desenvolvimento de artes plásticas.

Os itens dessa estrutura básica apresentam variáveis a cada encontro, de maneira que os pacientes tinham a opção de participar das atividades uma única vez, ou em todas as semanas, sempre às terças-feiras pela manhã. Foram onze encontros no total. Abaixo, descrevemos a rotina de atividades de alguns desses dias, procurando exemplificar possibilidades de intervenção a partir dessa estrutura. A rigor, foram escolhidos para a descrição encontros nos quais percebemos que a proposta foi bem recebida e que gerou mobilização artística e socializante nos pacientes.

\section{Primerio encontro: o novelo de lã}

As pessoas idosas, que esperavam para receberem tratamento odontológico, eram convidadas a sentarem-se ao redor de uma mesa; depois de sentadas, era feita a apresentação do projeto.

Feitos os devidos esclarecimentos, partia-se para a apresentação das pessoas, fazendo-se uso de um novelo de lã. Cada pessoa falava o seu nome enquanto segurava o fio 
do novelo e, em seguida, entregava desenrolando o novelo para outro participante. Dessa maneira, todos ficaram segurando o fio de lã, construindo uma teia. Depois, com o intuito de desfazer a teia de lã, cada participante deveria lembrar o nome do anterior (Figura 4).

As pessoas eram convidadas a pensar num lugar que tivesse sido importante e falar sobre ele para todos. $\mathrm{O}$ passo seguinte consistia em desenhar uma lembrança desse lugar; a este momento denominamos rastro plástico.

Nesse dia, as propostas abriram espaço para a sociabilização, permitindo a troca de experiências de vida entre os participantes. Entretanto, as moderadoras encontraram dificuldade para manter o foco em cada atividade de maneira que cada um pudesse mostrar aos outros seu desenho e sua história. Os assuntos resgatados pela memória durante o exercício transitavam entre viagens bem sucedidas, problemas de saúde superados e lembranças agradáveis (Figura 5 e Figura 6).

\section{Terceiro encontro: objetos cênicos}

Uma vez mais foi feito o convite para que as pessoas se sentassem em círculo, com cadeiras soltas, ao redor de uma mesa pequena e baixa, para participarem das atividades e foi feita a apresentação do projeto.

Propusemos que cada pessoa fizesse um pequeno desenho em uma folha de papel.

Alguns objetos cênicos como chapéus de época, coroa etc. foram dispostos na pequena mesa, no centro da roda. Todos eram convidados a observarem os objetos durante algum tempo. Em seguida, os objetos eram cobertos com uma toalha e cada pessoa deveria dizer três objetos que estivessem lá (Figura 7 ).

$O$ passo seguinte consistia em cada pessoa pegar um daqueles objetos cênicos e contar uma história real, ou ficcional, a partir do mesmo. O desafio ia aumentando de maneira que a mesma história deveria ser contada por cada integrante do grupo, incorporando seu objeto à trama.

O rastro plástico proposto foi que cada um desenhasse um objeto e escrevesse uma frase.

Figura 4 - Idoso contando parte de história com o novelo de lã em mãos.

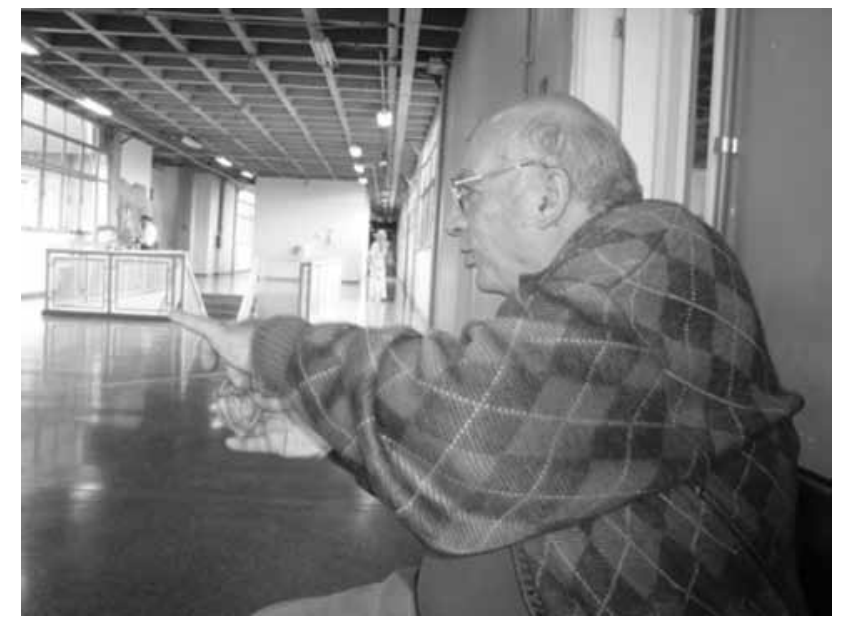



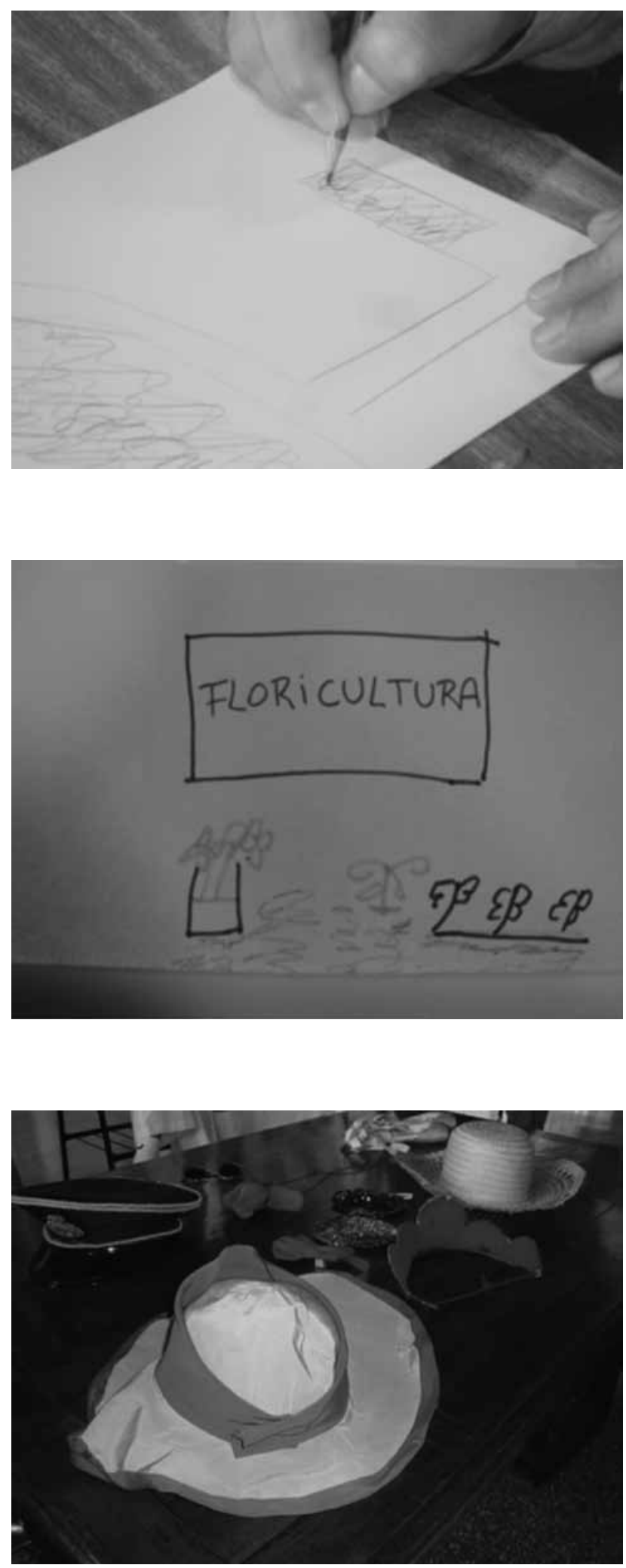

Figura 7 - Desafiando a

memória de contar história.

Figura 6 - Exemplo de

desenho de arte.

Figura 5 - Idoso expressando

em arte.

desenho de arte. 
Nesse dia, notamos que a materialidade do objeto era importante na relação entre memória e imaginação, propiciando um maior envolvimento com a atividade.

\section{Quinto encontro: a cidade feliz}

Após o convite a sentarem-se em carteiras universitárias, formando uma roda, e realizarmos a apresentação do projeto, sugerimos a cada um dos presentes que se apresentasse - "de onde vim, para onde vou" -. Cada um dizia seu nome, de onde veio e para onde iria depois da consulta.

Em uma mesa baixa, no centro da roda, colocamos alguns objetos: um pedaço de tule, um jornal, um buquê de flores, um envelope, um chapéu de cozinheiro, um avental de professor e um microfone.

Cada pessoa escolhia um objeto. Em seguida, apresentava o objeto para o grupo, explicitando sua forma e sua utilidade.

Elaboramos uma situação para o grupo: estávamos em uma cidade, e cada membro do grupo tinha a tarefa de dizer, a partir do objeto escolhido, qual a função de cada um naquela cidade e elaborar uma cena; por exemplo, a partir do chapéu de cozinheiro, a representação do restaurante.

Então, tendo canetinhas e giz de cera, cada pessoa iria confeccionar a placa de seu estabelecimento (Figura 8).

Pensamos em possíveis nomes para cidade, e um dos participantes sugeriu Cidade Feliz, nome prontamente aceito por todos.

Apresentamos uma de nós como sendo uma menina recém-chegada nesta cidade. A partir da pergunta "o que ela faz primeiro?", a personagem iniciou seu "passeio pela cidade", interagindo com os participantes que representavam os diversos estabelecimentos. Os participantes, como personagens, sugeriam as próximas ações da menina. O final da história se deu quando a menina terminou seu passeio e foi embora da cidade.

Nesse dia, percebemos um grande avanço na relação dos participantes em um espaço ficcional. Em geral, eles apresentaram certa facilidade em agir como personagens no espaço criado.

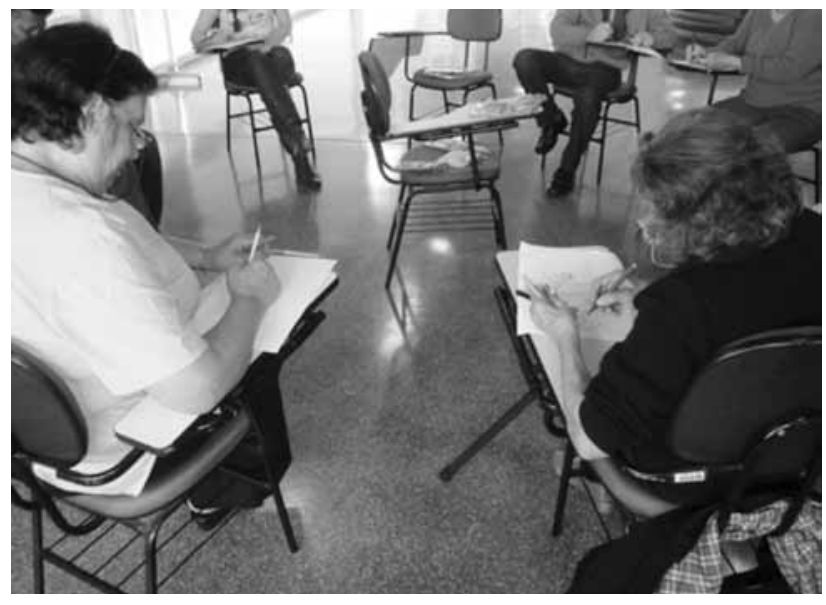

Figura 8 - Exemplo do uso da área de sala de espera. 


\section{Sétimo encontro: descobrindo as articulações}

Convidamos as pessoas a se sentarem em carteiras universitárias, formando uma roda, sem nada no centro, e apresentamos o projeto.

Propusemos um pequeno aquecimento corporal ao som de algumas músicas. $\mathrm{O}$ exercício corporal tinha início na percepção do modo de sentar na cadeira e se desenvolvia com foco nas articulações.

Usamos uma bola de tênis, que era passada de pessoa para pessoa, sempre a que estava ao lado. Ao passar a bola, a pessoa dizia seu próprio nome. Após algumas rodadas, passava-se a bola, dizendo o nome da pessoa que iria receber.

Dividimos os convidados em dois grupos e cada qual sorteou uma proposta de espaço e deveria construir uma estória que se passasse em tal lugar. Apareceram, então, um parque e um sítio. Cada uma das bolsistas ficou em um grupo, auxiliando no processo de criação.

Cada grupo contou para os participantes do outro grupo suas estórias. Em seguida, cada participante deveria fazer um desenho a partir da estória que ouviu e não daquela que construiu.

Nesse dia, buscamos retomar a questão da apresentação pela estratégia do desenho invertido. Assim, os participantes tiveram a oportunidade de se colocar artisticamente em relação à estória do outro.

\section{Décimo encontro: uma nova cidade}

Após o convite aos presentes - que se sentaram em carteiras universitárias, formando uma roda vazia no centro - e a apresentação do projeto, propusemos um pequeno aquecimento corporal ao som de algumas músicas. O exercício corporal tinha início na percepção do modo de sentar na cadeira e se desenvolvia com foco nas articulações.

Em roda, uma bola de tênis era passada para a pessoa que estava ao lado. Ao passar a bola, a pessoa dizia seu próprio nome. Após algumas rodadas, passava-se a bola dizendo o nome da pessoa que iria receber. Em seguida, a bola deveria ser arremessada para uma pessoa que estivesse distante na roda, dizendo o nome da pessoa que iria receber.

A partir de uma conversa, pensamos em diversos elementos que compõem uma cidade e cada um escolheu um estabelecimento para representar.

Feito isso, todos nomearam e construíram placas para seus "empreendimentos". A cidade contava com uma farmácia, uma quitanda, uma loja de materiais de construção e uma lanchonete.

Então, as duas bolsistas interpretaram duas pessoas que passeavam pela cidade. De lugar em lugar, desenvolveu-se uma trajetória dramática: uma das personagens passava mal, e, com a ajuda de todos os participantes (moradores da cidade), incluindo a outra personagem, ela melhorava.

Nesse dia, os participantes se envolveram bastante com a proposta, chegando a se colocarem fisicamente frente aos problemas da trama, assumindo uma postura cênica. 


\section{DISCUSSÃO}

Logo nos primeiros encontros, notamos a dificuldade dos participantes em construir espaços de ficção, fato que dificultava a transformação das memórias para linguagem artística. Então, buscamos trabalhar a questão da memória como matéria para criação, tendo sempre como foco a elaboração artística das lembranças em paralelo à ficção.

Além disso, percebemos que algumas mudanças possibilitavam melhor aproveitamento da atividade, como a retirada da mesa de centro, substituída por cadeiras universitárias, o que permitiu maior mobilidade dos participantes.

Foi uma grande descoberta para nós vislumbrar o prazer que aquelas pessoas sentiam ao colocar o corpo em ação, através do jogo com as bolinhas e dos exercícios das articulações. No início, tínhamos certo receio de trabalhar tal aspecto. Entretanto, logo percebemos o potencial dessas atividades para abrir caminho para o mergulho naquelas que seriam propostas em seguida.

No que concerne ao tratamento, percebemos em alguns casos a melhora na socialização dos idosos: no momento em que eram chamados para o atendimento, alguns chegaram a receber uma ovação do grupo, que sentia a perda de um membro daquele grupo. Por outro lado, ao adentrar para o tratamento específico, o idoso já estava mais descontraído, ativo e participativo das atividades clínicas necessárias ao bom andamento da terapêutica.

\section{CONCLUSÕES}

Durante o semestre no qual realizamos o trabalho prático, percebemos que nós (as propositoras) e os participantes (pacientes) conseguimos desenvolver um caminho de criação que a cada semana evoluía.

Aprendemos a importância da continuidade das atividades, pois, de um encontro para outro, pudemos aprofundar questões e descobrir elementos que funcionavam melhor para aquele espaço e para aquelas pessoas.

Outra melhoria que pode ser observada dizia respeito à troca de informações entre a equipe da sala de espera e o cirurgião-dentista, traduzida por uma melhora na relação entre o profissional de saúde e o paciente.

Como artistas, foi importante observar que a Arte está presente em cada um de nós, sendo que um trabalho de sensibilização pode fazer emergir memórias carregadas de valor poético.

Os cirurgiões-dentistas relataram que os pacientes se apresentavam menos ansiosos para as consultas. Foi possível observar que os mesmos não sentiam tanta necessidade de falar sobre situações aflitivas vivenciadas em tratamentos odontológicos realizados anteriormente. $\mathrm{O}$ tempo clínico rendeu mais e os pacientes se mostraram mais felizes.

O grupo acredita que estas atividades poderiam ser implementadas em todas as clínicas onde haja um grupo de pacientes em espera de atendimentos diversos, facilitando, assim, a dinâmica de relações entre o corpo clínico e os idosos ou pacientes. 


\section{REFERÊNCIAS BIBLIOGRÁFICAS}

[1] BENJAMIN, Walter. O narrador. Considerações sobre a obra de Nikolai Leskov. In: . Obras escolhidas: volume 1: magia e técnica, arte e política. Tradução, prefácio e notas de Jeanne Marie Gagnebin. São Paulo: Brasiliense, 2008. p. 197-221.

[2] BOSI, Ecléa. Memória e sociedade: lembranças de velhos. São Paulo: Companhia das Letras, 1994. 484 p.

[3] GARBUGLIO, Joyce Lukower. Sorrindo na melhor idade: uma abordagem atual da reabilitação oral na terceira idade. São Paulo: Santos Editora, 2009. 150 p.

Roberto Chaibj Stegun professor doutor da Faculdade de Odontologia da Universidade de São Paulo (FO-USP) e coordenador do programa Envelhecer Sorrindo - R. João Martins Ribeiro Filho, 375 - Jd.Adhemar de Barros - CEP 05540-04o - São Paulo SP - e-mail: rstegun@usp.br.

Maria Luiza Moreira Arantes Frigerio professora doutora da FO-USP e coordenadora do programa Envelhecer Sorrindo.

Eduardo T. Coutinho professor doutor do Departamento de Artes Cênicas da Escola de Comunicações e Artes da Universidade de São Paulo (ECA-USP).

Letícia de Paula Venâncio graduanda em Artes Cênicas pela ECA-USP.

Amanda Tavares Dias graduanda em Artes Cênicas pela ECA-USP.

Larissa Bergoli Galeazzi graduanda em Odontologia pela FO-USP.

Suzana Yumi Nakamura graduanda em Odontologia pela FO-USP. 